\title{
INTERFACES EPISTEMOLÓGICAS EMABORDAGENS INTER E TRANSDISCIPLINARES, EM REVITALIZAÇÃO DO AMBIENTE CONSTRUÍDO
}

\author{
COUTO, Heloísa Helena
}

Mestranda da Escola de Arquitetura da Universidade Federal de Minas Gerais (UFMG). Rua Dom Lúcio Antunes, 560/802 - Coração Eucarístico. Cep: 30535-630. Tel: (31) 3375-8258 e (31) 9967-1052.

E-mail: hhcriar@yahoo.com.br

\section{Resumo}

As deposições clandestinas indiscriminadas dos resíduos da construção civil (RCC) provocam danos enormes e irreparáveis prejuízos ao meio ambiente, causando poluição dos espaços públicos, encurtando a vidaútil dos aterros sanitários, promovendo o assoreamento de sub-bacias hidrográficas e onerando os cofres públicos. $\mathrm{O}$ objeto deste estudo é a gestão para lidar com os resíduos da construção civil, utilizando-os em intervenções residenciais de aglomerados urbanos. O estudo visa mostrar as interfaces epistemológicas em abordagens interdisciplinares e transdisciplinares do objeto de estudo proposto. A partir da epistemologia e dos conceitos de interdisciplinaridade e transdisciplinaridade procura-se identificar as disciplinas e suas interfaces com o objeto, fazendo uma breve contextualização sobre sustentabilidade e desenvolvimento econômico, materiais, resíduos de demolição, relações sociais. Reciclar resíduos da construção civil pode gerar programas de inclusão social, ao empregar e ao capacitar mão-de-obra desqualificada e também viabilizar a autogestão.

Palavras-chave: Interdisciplinaridade; Transdisciplinaridade; Sustentabilidade; Resíduos da construção civil; Meio ambiente.

\begin{abstract}
Indiscriminate clandestine depositions of construction wastes have produced enormous and irreparable damage to the environment, causing pollution of public urban areas, shortening the landfills' life cycle, promoting sedimentation of sub-watersheds and burden on public coffers. The object of this study is the management to deal with demolition wastes using them on residential interventions of urban cluster. This study aims to show the epistemological interfaces in Interdisciplinary and Transdisciplinary approaches of the object of study proposed. Based on the epistemology and on the concepts of interdisciplinarity and transdisciplinarity, we'llseek to identify the disciplines and their interfaces with the object, offering a brief background on sustainability and economic development, materials, construction waste, social relations. Recycling construction waste can generate social inclusion programs by employing and training disqualified human resources as well as enabling automanagement.
\end{abstract}

KEYWORDs: Interdisciplinarity; Transdisciplinarity; Sustainability; Construction waste; Environment. 


\section{INTRODUÇÃo}

Com o crescimento do setor da construção civil, as áreas de transbordos de resíduos - os bota-foras clandestinos em periferias da cidade, em lotes vagos, em anéis rodoviários e margens de rios que cortam os grandes centros metropolitanos - têm-se tornado um problema que contribui para a degradação da paisagem urbana e acaba por causar a poluição dos espaços públicos, comprometer o meio ambiente, encurtar a vida útil dos aterros sanitários e promover o assoreamento de sub-bacias hidrográficas, onerando os cofres públicos.

Nosso objeto de estudo será a gestão para lidar com os resíduos da construção civil (RCC), utilizandoos em intervenções no ambiente construído. O estudo em questão objetiva mostrar as interfaces epistemológicas em abordagens interdisciplinares e transdisciplinares do objeto de estudo proposto.

O programa de reciclar resíduos da construção civil tem gerado também a inclusão social, ao empregar e capacitar mão-de-obra desqualificada, ao viabilizar a autogestão e ao possibilitar projetos urbanos, ambientais e de sustentabilidade. $\mathrm{O}$ método adotado abordará os conceitos de interdisciplinaridade, transdisciplinaridade e a epistemologia sob a ótica de Santos (2003). A partir das Modalidades Cósmicas de Dooyeweerd (2006), de sua complexidade e interdependência, pretende-se identificar as disciplinas e suas interfaces com o objeto de estudo, na gestão e aplicação dos RCC como materiais alternativos, em intervenções no ambiente construído, fazendo uma breve contextualização sobre sustentabilidade e desenvolvimento econômico, materiais, resíduos de demolição, relações sociais.

A revisão bibliográfica consta de conceitos sobre interdisciplinaridade e transdisciplinaridade, baseandose na episteme do objeto de estudo abordado por Martins Junior (2006) e Santos (2003).

Abordaremos as disciplinas por ordem das modalidades, segundo as teorias de Dooyeweerd, apontadas por Martins Junior (2006).

Os materiais RCC serão estudados nas suas características e composição físico-químicas, e em suas propriedades mecânicas, com base nas teorias de Callister (1991) para os estudos dos pós. Os resíduos de demolição, a partir de Normas Técnicas Brasileiras (NBR's), das Cartilhas de Gestão dos Resíduos Sólidos do Sindicato da Indústria da Construção Civil (SindusCon) e do Conselho Regional de Engenharia, Arquitetura e Agronomia (Crea) e da Resolução 307 do Conselho Nacional do Meio Ambiente (Conama).

Será tratada também a ação participativa da comunidade, com a história de vida, experiências, características do público-alvo e suas culturas, tratadas por Brasil (2004) e Paugam (2003). As questões de políticas públicas, propondo um projeto de parceria público-privada entre os atores, serão abordadas pelas teorias de Gaudin (2005), Pereira (1999) e Fernandes (1998). A sustentabilidade, o desenvolvimento econômico e meio ambiente, sob a ótica de Veiga (1996) em uma abordagem de Altvater (1996), em $O$ Preço da Riqueza.

As relações sociais serão abordadas com ações participativas, articulação entre os diversos atores sociais e políticos e suas funções, baseados em Pereira \& Castriota (2005), juntamente com as teorias de Giddens tratadas por Asensi (2006), ainda contextualizando as relações sociais.

\section{EPISTEMologia}

\section{Paradigma dominante}

Santos (2003) afirma que a ciência racional hegemônica dominada pelas ciências naturais, com a revolução científica no século XVI, sofre a crise de sua hegemonia, rompendo com o senso comum. Somente no século XIX é que as ciências sociais emergentes assumem o modelo de racionalidade científica, em que houve a separação entre o sujeito e o objeto do conhecimento, isto é, o homem deixa de ser o objeto de conhecimento e passa ser o sujeito que pensa.

Descartes abre uma nova fase do conhecimento, mais rigorosa e profunda, a partir da matemática, que possibilita às ciências naturais análises, observações e experimentações mais precisas. A matemática vem aferir e fornecer como instrumento à ciência moderna o rigor científico das medições. 
Conhecer significa quantificar.

O método científico pauta pela redução da complexidade. A ciência moderna divide e classifica, isto é, quantifica e qualifica. Com as leis de Newton abrem-se novas perspectivas aos estudos da natureza, que possibilita o descobrimento das leis das sociedades (políticas e jurídicas) que governam a evolução da sociedade, que deram origem, no século XIX, às ciências sociais.

Eis alguns principais obstáculos: as ciências sociais não dispõem de teorias explicativas que lhe permitam abstrair do real para depois buscar nele, de modo metodologicamente controlado, a prova adequada; as ciências sociais não podem estabelecer leis universais porque os fenômenos sociais são historicamente condicionados e culturalmente determinados; as ciências sociais não podem produzir previsões fiáveis porque os seres humanos modificam seu comportamento em função do conhecimento que sobre ele se adquire; os fenômenos sociais são de natureza subjetiva e como tal não se deixam captar pela objetividade do comportamento; as ciências sociais não são objetivas porque o cientista social não pode libertar-se, no ato de observação, dos valores que informam a sua prática em geral e, portanto também a sua prática de cientista (NAGEL, 1961, p. 477 apud SANTOS, 2003, p. 36).

Com isso, Nagel demonstra que há diferenças entre as ciências sociais e as ciências naturais, elas não são lineares e são de difícil superação, daí a razão do atraso das ciências sociais em relação às ciências naturais.

Com Einstein vem o primeiro abalo do paradigma da ciência moderna, com a teoria da relatividade e simultaneidade, que revolucionou a concepção do espaço e tempo. Outra teoria de Einstein que impactou o paradigma dominante foi o da mecânica quântica de domínio da microfísica, da química e da biologia.

\section{Paradigma emergente da ciência moderna}

Santos (2003, p. 51-52) afirma que a teoria de
Prigogine, de um novo estado da matéria, propõe uma nova concepção da matéria e da natureza, dificilmente compatível com a física clássica existente até então.

Com a nova teoria, Pregogine recupera conceitos aristotélicos desprezados com a revolução científica do século XVI. Os conceitos de leis e casualidades são doravante questionados, as leis são insuficientes por apresentarem caráter probabilístico, aproximativo e provisório. Anoção de leis vai sendo substituída pelas noções de sistema, estruturas, modelo e, por último, processo.

A crise do paradigma da ciência moderna fundouse em condições teóricas e em condições sociais. A autonomia da ciência e o interesse pelo conhecimento científico fizeram-se abalar como evento do fenômeno da industrialização da própria ciência, em que o poder econômico, político e social passaram a exercer caráter decisório nas definições das prioridades científicas, manifestados em nível de suas aplicações como em nível da organização das investigações. Diante desse quadro se traçou uma relação de poder e autoridade entre a comunidade científica, submetendo-a a uma grande desigualdade. $\mathrm{O}$ desenvolvimento científicotecnológico é cada vez mais inacessível aos países pobres, agravando ainda mais a crise.

Santos, em seu trabalho (2003, p.62), diz que a crise do paradigma emergente não se apresenta de forma única científica, mas principalmente social, uma vez que brota da própria sociedade. Ele afirma que o paradigma é de um conhecimento científico prudente para uma vida decente. Que se atentarmos ao conteúdo teórico das ciências, se verifica que há uma emergente inteligência da natureza presidida por conceitos, teorias metáforas e analogias das ciências sociais.

A teoria das estruturas dissipativas de Pregogine e das teorias sinergéticas de Haken explicam os comportamentos das partículas por meio de conceitos de revolução social, como violência, escravatura, dominação, democracia nuclear, todos advindos das ciências sociais. O mesmo ocorre com a física e a psicanálise, na teoria de Capra, sendo reflexos um do outro.

Alguns autores atribuemà natureza um comportamento 
humano. Ainda citando Santos (2003):

A concepção humanística das ciências sociais enquanto agente catalisador da progressiva fusão das ciências naturais e ciências sociais colocam a pessoa, enquanto autor e sujeito do mundo, no centro do conhecimento, mas, ao contrário das humanidades tradicionais, coloca o que hoje designamos por natureza humana no centro da pessoa. Não há natureza humana porque toda natureza é humana (SANTOS, 2003, p. 71-72).

Santos (2003) afirma ainda que a ciência pósmoderna é uma ciência analógica, em que o mundo é visto através do imaginário: hoje ele é natural ou social, amanhã poderá ser ambos. O mundo é como um jogo, um palco onde serão exercitados textos ou biografias como comunicação, onde a lógica existencial da ciência pós-moderna será a 'situação comunicativa'. Tudo dependerá das configurações de analogias que imaginarmos.

A ciência moderna evolui no conhecimento especialista, legitimando o reducionismo quantitativo e tecnocrático. O conhecimento é parcelado e reduzido, o saber científico é arbitrariamente disciplinar. Que segundo a visão de Santos (2003, p. 74), esta divisão do saber acarreta males, "o saber científico faz do cientista um ignorante especializado". Para que este erro fosse corrigido, criaram-se novas disciplinas, mas sem grandes êxitos.

No paradigma emergente, o conhecimento é a totalidade universal, indivisa e local, constituído por temas adotados por grupos sociais. O paradigma pósmoderno é fragmentado por temas e não por disciplinas. Os temas são percursos por onde o conhecimento avança a procura de novas e das mais diversas interfaces.

O conhecimento pós-moderno é projetado sobre as condições e possibilidades das ações humanas a partir de um espaço-tempo local. Esse tipo de conhecimento é imetódico, conseguido a partir de uma pluralidade metodológica, em que cada método corresponde a uma linguagem e a realidade responde conforme a língua na qualé feita a pergunta.

Para se entender a transição da revolução científica dos novos tempos, de multidisciplinas e de pluraridades de métodos, Santos (2003, p.78) nos fala de uma transgressão metodológica. Esta repercute nos estilos e gêneros literários que dirigem a escrita científica. $\mathrm{Na}$ ciência pós-moderna, o cientista não contará com um estilo unidimensional ele construirá seu próprio estilo, configurando-os segundo os seus critérios e a imaginação.

\section{Inter e Transdisciplinaridade}

Segundo Alves e Brito (2004), a interdisciplinaridade é apontada como saída para o problema da disciplinaridade, com a presença de profissionais de várias áreas como necessidade inerente ao projeto interdisciplinar. Trata-se da presença de equipes multidisciplinares para o desenvolvimento de projetos de pesquisa.

Japiassú foi o responsável por introduzir, no Brasil, a partir de 1976, as concepções sobre interdisciplinaridade, decorrentes do Congresso de Nice, na França, em 1969. Japiassú e Ivani Fazenda são considerados responsáveis pela veiculação do tema no Brasil, sendo o fulcro temático de Japiassú epistemológico, e o de Fazenda, pedagógico; entretanto, os dois autores têm como base de suas teses a filosofia do sujeito (ALVES; BRITO, 2004).

A interdisciplinaridade traz consigo um produto do processo de construção do conhecimento, incluindo a disciplinaridade como etapa dessa construção do diálogo entre as disciplinas.

A multidisciplinariedade indica a prática do diálogo multiprofissional, concebido como possibilidade de estabelecer um veio de comunicação entre os diversos campos do conhecimento, permitindo níveis de contribuição e entendimento entre as disciplinas, de modo a garantir a compreensão cada vez mais clara dos objetos de pesquisa. Segundo Japiassú (1976) apud Alves; Brito (2004, p. 141): 
À interdisciplinaridade faz-se mister a intercomunicação entre as disciplinas, de modo que resulte uma modificação entre elas, através de diálogo compreensível, uma vez que a simples troca de informações entre organizações disciplinares não constitui um método interdisciplinar.

A transdisciplinaridade promove a dissolução dos discursos homogeneizantes na ciência e na cultura: ela é uma abordagem científica que visa à unidade do conhecimento. Dessa forma, procura articular uma nova compreensão da realidade, combinando elementos que passam entre, além e através das disciplinas, numa busca de compreensão da complexidade dos fenômenos científicos.

\section{A ciência moderna e a epistemologia Dooyeweerdiana}

As obras de Dooyeweerd muito contribuíram para o pensamento epistemológico e filosófico ocidental contemporâneo, relativo aos conceitos de sistemas e da perspectiva interdisciplinar, denominada Escola da Idéia Cosmonômica.

A característica desta escola é abordar sistematicamente os diversos aspectos da realidade, denominando-os de modalidades, aspectos modais ou ainda esferas de soberania. [...] Outros termos não menos importantes para apreensão da realidade são: os sujeitos, os objetos, as leis, as normas o desdobramentos ou evolução, as tipicalidades, a liberdade, as antinomias, a soberania a universalidade das modalidades, o reducionismo as analogias, as leis de antecipação e de retrocipação e as leis nucleares (MARTINS JUNIOR, 2006, p.70).

As Modalidades Cósmicas, baseadas nas teorias, segundo Dooyeweerd (1969, p.4) apud Martins Junior (2006, p. 70-71), afirmam que "a realidade é significado". Onde:

Realidadı $\rightarrow$ todo e o significado $\rightarrow$ são dados pelo conjunto das partes. Com o todo é composto pelas partes, então a "realidade é significado".

O significado dos fenômenos só será possível ser apreendido a partir da união das partes que compõem o todo (fenômeno). As partes neste contexto darão o significado ao todo. A compreensão da realidade só é possível pela inter-relatividade e na intersubjetividade, pois nada é absolutamente ideal, nada é reduzido à matéria e nada é relativo, mas tudo está interrelacionado por suas partes.

\section{As Modalidades Cósmicas, sua complexidade e interdependências}

Levando-se em conta que tudo o que se observa no mundo real só fará sentido em relação ao outro, ou a algo e que a realidade é o todo indivisa e una, concluise que a realidade nos apresenta como aspectos e modos próprios de ser ou de se relacionar sob algum aspecto com esta realidade.

Segundo Martins Junior (2006, p. 71), Modalidades Cósmicas são aspectos que se permitem limitar como sendo subconjunto de coisas e de relações que se caracterizam por coerência e unidade própria, perceptíveis de modo distinto de outra modalidade, apesar de se inter-relacionarem. Elas apresentam status de soberania, ocupamo topo da cadeia, diferentemente do status de autonomia, pelo fato de tudo se apresentar relacionado a tudo. Cada modalidade possui sua lei própria e a sua maneira própria de relacionar-se. À medida que essas leis que as regem sejam consideradas universais, dão-lhes o caráter de soberania.

É o conjunto ou espectro de realidade das coisas e de relações características, regidas por leis próprias, por relações próprias, por características únicas irredutíveis a outras modalidades (Dooyeweerd, 1958 apud Martins Junior, 2006, p.71).

As modalidades são compostas de sujeitos, objetos, coisas, relações ou funções que se formam como que em um mundo próprio, que nos permitem identificar como os grandes conjuntos de coisas se relacionam e se constituem, apesar de características próprias, únicas e inconfundíveis. 
Segundo Martins Junior (2006, p. 73), as modalidades estão enumeradas em ordem de complexidade e de interdependências, obedecendo a uma sequência existencial, no aspecto da gênese e no aspecto de interdependência.

Na Figura 1 estão identificadas 15 modalidades segundo teorias de Dooyeweerd, em que as ciências especialistas estudam as modalidades ou conjuntos específicos de aspectos de uma única modalidade. Cada uma delas, na ordem sequencial, é substrato à existência da outra modalidade, em seu aspecto multidisciplinar. As relações entre as modalidades formam a interdisciplinaridade. A transversalidade está representada pelas relações ortogonais triaxial entre os sujeitos (entidades), sujeitos às leis que regem cada uma das modalidades, as tipicalidades e os objetos.

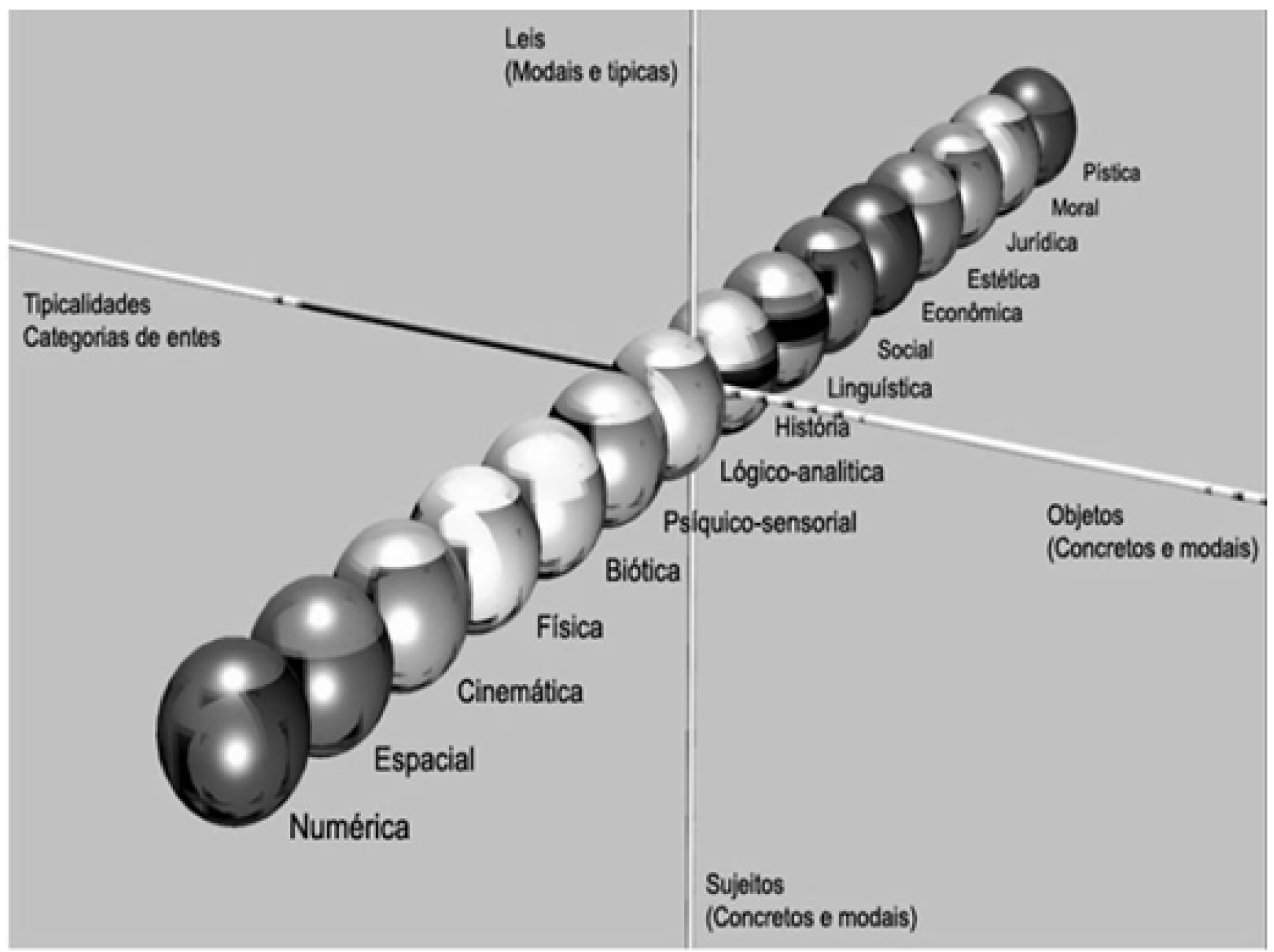

Figura 1 - Representação tri-axial das relações ortogonais e irredutíveis entre sujeitos, leis, modalidades, tipicalidades e objetos.

Fonte: Martins Junior, P.P. \& Freire, S.A.

As leis que regem as modalidades são entendidas como: as leis naturais e as leis sociais, ou normativas.

As leis da natureza (o limite entre o criador e a natureza) não podem ser transgredidas, são determinantes da evolução do cosmos. Essas leis são descobertas e regem as modalidades fundamentais ou elementares: numérica, espacial, cinemática e física e biótica. 
As leis sociais ou normativas regem as modalidades pós-bióticas, de onde começa a vida: psíquicosensorial, lógico-analítico, história, linguística, social, econômica, estética, jurídica, moral e pística. Essas normas podem ser respeitadas ou não. Quando desrespeitadas paga-se um alto custo social.

A diferença entre tipicalidade e modalidade está na questão relacionada às leis, cuja aplicação restringe as descrições de estruturas de uma classe limitada de sujeitos, denominadas de leis típicas. Eas leis modais aplicam-se a todas as classes de sujeitos e objetos independentes de suas estruturas: são leis que descrevem modos de ser, relacionamentos, experiências ou explanações. A forma pelas quais elas são reconhecíveis:

$\checkmark$ Leis típicas são descobertas por indução e generalização dos fatos empíricos.

$\checkmark$ Leis modais são descobertas por abstração.

Segundo Martins Junior (2006, p. 85), seres humanos são todos sujeitos em todas as modalidades. Sujeito é toda e qualquer entidade sujeita às leis de alguma modalidade. O ser humano compreende todas as modalidades, definindo-se no seu Ponto Arquimediano, o Cerne de seu ser.

O objeto é entendido a partir de uma relação de serventia de um ser ou sujeito, com outro ser ou objeto, que se define em outra modalidade mais complexa.

\section{As modalidades e seus núcleos significantes}

Foram identificadas no objeto deste estudo as seguintes Modalidades Cósmicas.

$\checkmark$ Física (abrangendo a energia e a matéria) - no desenvolvimento tecnológico dos compósitos de RCC, sendo estudadas suas propriedades físico-mecânicas na realização de testes laboratoriais, colhendo os dados empíricos em testes relacionados às Engenharias dos Materiais e Civil.

$\checkmark$ Biótica (os fenômenos orgânicos, matérias bióticas ligados à vida, biologia, química, zoologia, geologia) - quanto ao desenvolvimento tecnológico dos compósitos de RCC, serão realizados em laboratórios os testes das características químicas dos pós de entulhos, comas Engenharias dos Materiais e Química na confecção de novos produtos e compósitos a partir dos agregados resíduos.

$\checkmark$ Social (na constituição da comunidade enquanto grupo social, expressando a sua sociabilização e comunicação) - o potencial do ser humano de se agregar e de se constituir humano, a partir da capacidade de seres próprios e agregados. Identificamse na sociologia os estudos culturais da comunidade, suas relações e capacidades potenciais.

$\checkmark$ Econômica (as frugalidades em gerenciar recursos escassos ou de poupança) - visto pelo viés do Desenvolvimento Sustentável e Ecológico e Econômico. Quando analisados, a gestão ambiental dos resíduos da construção, o ecoproduto, a análise de ciclo de vida do produto e o empreendedorismo.

$\checkmark$ Estética (com a ideia e os sentimentos de beleza, abordados pelo princípio básico da harmonia) - nela pode-se destacar a Engenharia Civil, a Arquitetura e o Design, nas técnicas construtivas, na concepção do conforto e ergonomia, no embelezamento do espaço comum e individual, na eficácia dos produtos e de suas relações com o homem. Essas disciplinas estarão presentes no estudo de caso, como intervenção de revitalização do ambiente construído e como materiais alternativos empregados na revitalização, a partir dos resíduos de demolições.

$\checkmark$ Jurídica (implica a dimensão de regulação das relações sociais, princípios de justiça, de retribuição e de direitos) - abordam-se aqui as normas sociais na Sociologia e no Direito Político, com as Políticas Públicas, Geografia e Arquitetura (Meio Antrópico). Visando à articulação dos diversos atores sociais, públicos e suas funções, a participação popular, a inclusão social e por último uma possível parceria público-privada.

\section{Disciplinas e suas interfaces}

Busca-se a identificação das disciplinas e sua interdependência como objeto de estudo, na gestão e aplicação dos RCC como materiais alternativos na construção civil.

\section{Física e Química e Engenharia de Materiais}

Quanto à análise comparativa laboratorial dos 
compósitos químicos estruturais e as propriedades mecânicas (tonalidade, porosidade, absorção, densidade e deformação) dos corpos de prova, conforme consultas em Normas Técnicas Brasileiras (NBRs) e metodologia da Engenharia de Materiais, em que se consultam referências (no Callister) sobre processos de produção de compósitos de diferentes tipos de pó. Os trabalhos de Cassa et al. (2001) serão tomados como parâmetros de estudos.

\section{Economia, Meio ambiente e Ecodesign}

No processo de transformação dos materiais são produzidos rejeitos, sendo possível a alguns deles a reciclagem. A capacidade de reelaboração e de absorção da natureza é diretamente proporcional à medida de como esses rejeitos vêm sendo acumulados no meio ambiente. Nesse processo de transformação, a reserva de energia é degradada (sintropia) e a capacidade de reelaboração dos rejeitos, na natureza, é definitivamente diminuída. Ainda neste processo, os fluxos energéticos vão impulsionar os sistemas vitais básicos (físicos, químicos e biológicos), afetando o ar, a água, e o solo com a emissão de carbono e outro gás danoso ao meio ambiente, como o ozônio. A incapacidade de reelaboração dos sistemas é como um freio, limitando a velocidade e as atividades humanas no desenvolvimento econômico global, em longo prazo.

Deverá ser levada em conta a gestão dos resíduos sólidos como instrumento econômico. Visto pelo viés das cartilhas de gestão do Crea, SindusCon, da Resolução Conama e a prefeitura.

A gestão de articulação desses atores sociais e estatais é fator fundamental e relevante na aplicação e/ ou utilização de compósitos derivados dos Resíduos da Construção Civil (RCC).

A fim de buscar maior viabilidade econômica e minimizar gastos com energia e matéria-prima, utilizarse-á posteriormente da análise do ciclo de vida dos materiais.

O estudo do ciclo de vida, do material agregado a ser desenvolvido, ou dos resíduos brutos da construção civil, será baseado na Série ISO 14000. Como o material é um compósito, cada parte integrante dele deve ter sua Avaliação de Ciclo de Vida (ACV), especialmente para a questão de geração de resíduos sólidos. Seria uma análise desde o início da extração da matéria prima até o seu descarte, do berço ao túmulo.

O design contemporâneo caracteriza-se ainda pela responsabilidade socioambiental, devendo impulsionar a indústria da reciclagem, o turismo, dar novas formas ao artesanato, gerar rendas e inclusão social. Nesse aspecto se pode desenvolver o empreendedorismo, com ações voltadas à capacitação de mão-de-obra na própria comunidade, formando parcerias público- privadas na constituição de incubadoras comunitárias.

\section{A Sociologia e o Direto Político}

O Meio Antrópico, com as Políticas Públicas, Geografia e Arquitetura, leva-nos a refletir: no contexto social-econômico, a teoria de Giddens possibilita-nos a compreender a sociedade moderna e sua relação estruturada, ao longo do tempo, do espaço com o meio ambiente, tendo a democracia como um instrumento de transformação da coletividade. Giddens afirma que os indivíduos, através de uma mediação, agem coletivamente para modificar os padrões existentes, que o autor chama de força ontológica.

A noção de força ontológica diz respeito ao fato do indivíduo, enquanto membro de uma coletividade, ter capacidade de transformar através de sua ação as coisas, atuando reflexivamente em uma estrutura. Em outras palavras, esta noção procura dar conta do grau de interferência do indivíduo nas transformações sociais, (...) Sociologicamente, podemos destacar duas esferas de atuação dos indivíduos: institucionalmente ou particularmente. (GIDDENS, 2006 apud ASENSI, 2006).

Entende-se na teoria de Giddens que o indivíduo isolado não tem força para mudar uma estrutura, no caso, os paradigmas sociais ou ambientais, mas o indivíduo inserido na coletividade organizada institucionalmente possui todas as capacidades de 
mudanças dessas estruturas, a partir de sua força coletiva da argumentação.

Entre os resultados positivos das práticas de gestão ambiental destacam-se aqueles que promovem a inclusão social de camadas populacionais marginalizadas por meio da geração de empregos, aumento da consciência ambiental, ampliação e fortalecimento da co-responsabilidade da sociedade na fiscalização e controle dos agentes responsáveis pela degradação socioambiental, redução dos impactos ambientais derivados das atividades econômicas, no caso específico deste trabalho, as atividades da construção civil.

Uma das formas de inclusão social implementadas pela Prefeitura de Belo Horizonte, por meio de políticas e práticas de gestão dos resíduos da construção civil, foi a implementação da fábrica de produção de artefatos de concreto, em que são utilizados agregados reciclados como matéria-prima.

O projeto em questão teria como meta inclusão social, reciclagem e empreendedorismo, a partir de um novo material, a ser desenvolvido pela pesquisa, além de introduzir novos produtos, gerados da reciclagem de resíduos da construção civil.

\section{Políticas Públicas}

Brasil (2004) aborda alguns conceitos pertinentes no contexto das políticas urbanas. Entre eles a noção de territorialidade, território e espaço social. Ela cita alguns autores para explicá-los:

Milton Campos destaca o caráter jurídico-político deste termo, vinculado ao Estado-nação. [...] A noção moderna de território refere-se ao espaço imbuído da dimensão de soberania e poder do Estado, traduzindo-se no estabelecimento de limites geopolíticos e na dimensão da propriedade. Associa-se, ainda à ideia de pertencimento e de referência de identidade, bem como a cidadania, que expressa a relação entre o lugar e o cidadão. [...] o conceito de território apresenta-se como utilizável e relevante para análise social, somente se considerado seu uso, a relação dissociável com os atores sociais que dele se utilizam convocando a dimensão do vivido.

Se levarmos em conta o uso e a apropriação, território, no âmbito das ciências biológicas será considerado a área e os limites da influência das espécies (BRASIL, 2004).

No Brasil, a Constituição de 1988 marcou a democracia com uma nova forma de participação e descentralização das políticas públicas, a partir de conjuntos de formas ampliadas de participação política e de instituições híbridas, em que atores estatais, atores sociais e associações da sociedade civil se reorganizam em nível local, debatendo estratégicas através de ações coletivas, compartilhadas e negociadas.

A partir da Constituição de 1988, os planos são legitimados pela participação popular; representam a vontade do povo, onde o técnico passa a agir como consultor e mediador, envolvendo a participação de atores políticos, atores sociais e parceiros públicos privados.

Baseado em citações de Brasil (2004) sobre os vínculos entre territórios, as segregações socioespaciais e a exclusão podem gerar mais problemas, quando as condições das moradias, tanto internas quanto externas, representam uma visão negativa para os moradores, considerada sob o ponto de vista de vizinhanças e em relação a certas áreas das cidades. Isso geraria a estigmatização e a desqualificação desses moradores, aumentando ainda mais a exclusão social e caracterizando bolsões de privação, como os problemas de desemprego, educação, moradia, saúde e criminalidade.

Essas vizinhanças têm características particulares e específicas, como: localização, acessos aos serviços, bases socioeconômicas, equipamentos urbanos e padrão habitacional, que vão impactar opiniões, comportamentos, atitudes e reduzir oportunidades. Diante da imagem negativa e de precariedade, a área apresentará aos olhos da população uma reputação duvidosa, que gerará degradação urbano-ambiental e socioespacial.

Em seus estudos, Paugam (2003) apud Brasil 
(2004) confirma a apresentação de identidades sociais negativas, vinculadas ao traço de desvalorização e degradação local assinalada a um pertencimento de um estrato inferior.

Intervir nesses espaços urbanos requer uma política participativa, fundada em sistemas de governança, de respeito ao cidadão, com uma abordagem plural e com parceria público-privada.

Finalmente deverá ser proposto um projeto de parceria público-privada entre os atores, em que serão assegurados o alcance dos objetivos, os mecanismos de prestação de contas e de controle das funções de cada ator envolvido, com um contrato social de fechamento.

\section{Conclusões}

A ciência moderna lida com sistemas complexos, em que ao final dos processos ocorrem sínteses, partes do sistema de cognição. Normalmente são sínteses pluridisciplinares, requerendo, para melhor apreensão do fenômeno, uma síntese interdisciplinar.

Elas se diferem quanto ao modo de observar o objeto e em considerar sua complexidade, seja ela uma coisa ou um fenômeno, em que diversos campos de cognição são invocados a observar e identificar, a partir de um viés da ciência especialista, com suas respectivas metodologias, uma abordagem integrada por meio de um sistema de inquirição (diversos modos de se definir o que seja uma verdade e como acessá-la na prática científica).

O objeto aqui analisado deverá ser visto pelo viés da transdisciplinaridade e da interdisciplinaridade, por tratar de problemas contemporâneos complexos e pluridisciplinares.

O planejamento e o monitoramento com a participação coletiva, envolvendo atores sociais e políticos como parte da postura política dessa governabilidade, será muito importante na busca de resultados, das metas, de cumprimentos de prazos, dos recursos e de responsabilidades.

O baixo padrão habitacional dos aglomerados de baixa renda é um dos fatores de estigmatização de áreas: desqualifica os cidadãos e suas vizinhanças, impacta atitudes, comportamentos e reduz as oportunidades agravando o processo de exclusão social, segundo Brasil (2004). A revitalização do espaço construído promoverá uma maior qualificação social, contribuirá para a autoestima dos moradores e diminuirá a degradação socioespacial.

Contudo, a intervenção proporcionará o melhoramento ambiental, segurança, conforto e sustentabilidade social e ambiental, dando com isso uma utilização mais eficaz aos resíduos da construção civil (RCC).

\section{REFERÊNCIAS}

ALTEVATER, Elmar. O Preço da Riqueza: Pilhagem ambiental e a nova (des)ordem mundial. Trad. Em português Wolfgang Editora. UNESP, 1996.

ALVES, Brasileiro; BRITO. Interdisciplinaridade: Um conceito em construção. Disponível em: <www.ilea.ufrgs.br/.../

episteme19_artigo_alves_brasileiro_brito.pdf,> acessado em Novembro de 2009.

ASENSI, Felipe Dutra. Teoria da estruturação e

ação coletiva: Uma exegese sobre a obra de Anthony Giddens, 2006. Disponível em, <http:// www.duplipensar.net/artigos/2006-Q2/anthonygiddens-teoria-da-estruturacao-e-acaocoletiva.html>, acessado em 25/07/2007.

AVRITZER, Leonardo; PEREIRA, M. de Lourdes D. Democracia, participação e instituições híbridas. Teoria e Sociedade. Revista dos departamentos de Ciências Políticas e de Sociologia e AntropologiaUFMG. Belo Horizonte, n.esp. p. 16-41, 2005.

BRASIL, Flávia. Território e Territorialidades nas Políticas Sociais. Gestão Social: o que há de novo? Belo Horizonte. Ed. FJP/BNDS/PBH, 2004. v. 1, p. $45-66$.

CALLISTER, WILLIAM D. Ciência e 
Engenharia de Materiais: Uma introdução. Wiley: Nova York, LTC, 2002.

CASSA. José Clodoaldo da Silva; Org. por CARNEIRO, Alex Pires; BRUM, Irineu Antônio Schadach de. Reciclagem de entulho para produção de materiais de construção. Salvador: EDUFBA, 2001.312 p.

CONAMA, 2002. Disponível em: $<$ http://www.cetesb.sp.gov.br/licenciamentoo/ legislacao/federal/resolucoes/ 2002_Res_CONAMA_307.pdf $>$, acessado em Outubro de 2008.

CUNHA, Lúcia Helena de Oliveira. Diálogo entre saberes. Disponível em: http://ojs.c3sl.ufpr.br/ojs2/index.php/made/article/ viewFile/3041/2432, acessado em Novembro de 2009.

DOOYEWEERD, H. A. New critique of theoretical thought: presbyterian an reformed publishing: In: MARTINS JUNIOR, Paulo Pereira. Epistemologia fundamental, um estudo introdutório sobre a estrutura do conhecimento e a aplicação prática da epistemología na pesquisa científica, 2006. (Apostila Pré-livro)

FERNANDES, Edésio (org.). Direito Urbanístico. Belo Horizonte: Del Rey Ed, 1998.

GAUDIN, J.P. . O significado do contrato nas políticas públicas. Revista Teoria e Sociedade, $n$. esp. BH. ED. UFMG. p. 42-55, 2005.

GIDDENS, ASENSI. Em Teoria da estruturação e ação coletiva: Uma exegese sobre a obra de Anthony Giddens, 2006. Disponível em, <http://www.duplipensar.net/ artigos/2006-Q2/anthony-giddens-teoria-daestruturacao-e-acao-coletiva.html>, acessado em 25/07/2007.
JAPIASSÚ, H. Interdisciplinaridade e patologia do saber. Rio de Janeiro: Imago, 1976.

Nascimento e morte das ciências

humanas. Rio de Janeiro: Francisco Alves, 1982.

. A crise da razão e do saber objetivo: as ondas do irracional. São Paulo: Letras \& Letras, 1996. In: ALVES, Brasileiro; BRITO. Interdisciplinaridade: Um conceito em construção, 2005. Disponível em: <www.ilea.ufrgs.br/.../ episteme19_artigo_alves_brasileiro_brito.pdf $>$, acessado em Nov. de 2009.

LEFF, E. Epistemologia ambiental. São Paulo: Cortez, 2001.

MARTINS JUNIOR, Paulo Pereira. Epistemologia Fundamental, um Estudo Introdutório sobre a Estrutura do Conhecimento e a Aplicação Prática da Epistemologia na Pesquisa Científica. (Apostila Pré-Livro), 2006.

PAUGAM, Serge. Desqualificação social: ensaio sobre a nova pobreza. São Paulo: Cortez, 2003. In: BRASIL, Flávia. Território e Territorialidades nas Políticas Sociais. Gestão Social: o que há de novo? Belo Horizonte. Ed. FJP/BNDS/PBH., 2004. v. 1, p. 45-66.

PEREIRA, Maria de Lourdes. Negociações e Parcerias: a gestão democrática urbanoparticipativa. Dissertação- (Doutorado em Ciencia Política)- Universidade de São Paulo, 1999.

PEREIRA, Maria de Lourdes; CASTRIOTA, Leonardo. Fóruns de negociação com a comunidade: um novo formato de exercício da democracia in ética, planejamento e construção da democracia do espaço. In: ENCONTRO NACIONAL DAANPUR, 9. Anais. Rio de Janeiro, 2001. p. 1228-1239. 
PREFEITUIRA DE BELO HORIZONTE. Lixo: Um grave problema do mundo moderno, 2004. Disponível em: <http//:www.pbh.gov.br>, acessado em Out. de 2008.

SANTOS, Boaventura de Souza. Um discurso sobre as ciências. São Paulo: Cortez, 2003.
VEIGA, José Eli da. O que pode ser um Green New Deal? In Análise, maio de 2009. Disponível em: $<$ http://www.econ.fea.usp.br/zeeli/artigos/pagina22/ Na\%20PAGINA22\%20de\%20Maio\%202009.pdf>, acesso em 11/05/2009.

VEIGA, José Eli da. Do global ao Local. São Paulo: Editora Armazem do Ipê. 2005, 119 p.

RECEBIDO EM 24/5/2010

ACEITO EM 18/7/2010 